ESTUDOS LINGÜIISTICOS 


\title{
O FALANTE: QUE BICHO É ESSE, AFINAL?*
}

\author{
Carlos Alberto Faraco** \\ Lígia Negri**
}

\section{Introdução}

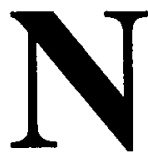

o estudo dos fenômenos lingüísticos, estamos acostumados (seja pela tradição gramatical, seja pela Lingüística moderna) a pensar que existe uma língua una (um sistema gramatical abstrato), e que falar é apenas atualizar individualmente as virtualidades desse sistema.

O falante que realiza essa instanciação do sistema raramente foi visto pelos estudos lingüísticos como um ente problemático: ele/ela conhece a língua, isto é, tem uma competência gramatical e utiliza essa competência para falar e entender.

Se formos um pouco mais a fundo, veremos que o falante é um ente sobre o qual sempre se disse muito pouco em Lingüística.

Mesmo quando, na Dialetologia e na Sociolingüística, o falante parece surgir como elemento relevante para o estudo de fenômenos lingüísticos, não se vai, de fato, muito além de um ser genérico e quase abstrato, em quem interessa tão somente identificar algumas poucas características de sua situação no mundo e observar uma eventual repercussão dessas características sobre sua pronúncia,

* A primeira versão deste texto foi escrita para orientar as discussões teóricas da disciplina optativa Língua Portuguesa X, ofertada por nós aos alunos do curso de Letras da UFPR, no segundo semestre de 1997. O programa desenvolvido abordou o tema da citação, envolvendo a análise de sua ocorrência em diferentes práticas discursivas. Na elaboração deste texto, optamos por uma forma mais próxima do ensaio do que do artigo acadêmico. Em razão disso, nossas referências bibliográficas não estão apresentadas de forma pontual, mas arroladas, em nota, no início das seções.

** Universidade Federal do Paraná 
sua sintaxe e seu vocabulário. Esses estudos, na verdade, dão atenção aos elementos lingüísticos em variação e não propriamente ao falante. Este continua aí a ser um ente não problemático, a respeito de quem pouco se precisa dizer.

Todas as discussões correntes nos séculos 19 e 20 que problematizaram as concepções tradicionais da pessoa humana não chegaram a ter efetiva repercussão no interior da Lingüística.

De certo modo, essa situação é perfeitamente compreensível, se lembrarmos que a Lingüística se constituiu historicamente como a ciência que centra sua atenção sobre a língua em si, vista como um código autônomo e autoregulado. Nesse quadro epistemológico, problematizar o falante é irrelevante. Daí que a concepção tradicional de pessoa humana (transformada em elemento de senso comum) é o limite máximo de eventuais asserções que os lingüistas cheguem a fazer sobre o falante.

Nelas, o falante não passa de uma superfície linguística plana (univocal). É entendido como um ente autônomo (suas relações sociais são, em geral, acessórias; quando não de todo irrelevantes); como a origem absoluta da fala (o olhar dos linguiistas é fortemente unidirecional e monológico: o falante tem total precedência sobre o ouvinte e sobre a interlocução); e como uniforme interiormente (o máximo que se diz sobre o mundo interior do falante é que ele tem um saber gramatical específico que lhe permite a fala).

Podemos dizer, sem maiores problemas, que a imagem que permanece soberana, quando é necessário mencionar o falante nos estudos lingüísticos, é aquela do indivíduo construída pelo pensamento pós-medieval. Assim, antes de explicitarmos uma imagem alternativa, é interessante percorrer um pouco os vários caminhos que contribuíram seja para a construção daquela imagem, seja para sua crítica posterior.

\section{A imagem moderna (pós-medieval) da pessoa humana ${ }^{1}$}

A imagem que poderíamos chamar de moderna da pessoa humana foi sendo elaborada à medida que desmoronava o mundo medieval. Neste, o ser humano era entendido como uma criatura que exerce uma função específica numa ordem social estática, cumprindo, assim, um determinado plano divino e se preparando para a vida pós-morte. PEASE.

1 Baseamo-nos, para esta seção, nos seguintes autores: DUMONT, HANSEN e 
Os inúmeros fatores históricos que contribuíram para o fim do mundo medieval produziram também e por consequiência um deslocamento do eixo de percepção do ser humano para um ângulo que reforçou exatamente sua individualidade acima de sua função ou de seu lugar numa rígida sociedade hierarquizada ou num mundo tido como criado e estático.

O humanismo renascentista, com sua revalorização da cultura grecoromana naquilo que ela favorecia, pelos seus aspectos antropocêntricos, essa nova percepção; e as elaborações da Reforma religiosa do século 16, ao defender o princípio da relação direta e individual da pessoa com Deus, livre da mediação institucional da Igreja, são dois grandes momentos desse longo e complexo processo de reconceitualização do ser humano.

No século 17, as novas práticas científicas, que se desenvolviam desde o século anterior, vão colocar a razão humana no centro das atividades intelectuais, desembocando, aos poucos, numa espécie de culto à Razão. Essas mesmas práticas vão também favorecer a elaboração de uma teoria do conhecimento que, refinada aqui e ali, continua, de certa forma, a orientar nossa compreensão dos processos cognitivos e que tem na sua base a noção de sujeito pensante, geralmente entendido como uma consciência individual e autônoma que, num vácuo social e histórico, age sobre os objetos externos ou a eles reage.

No século 18, a nova forma de percepção do ser humano vai sustentar a constituição de um pensamento político que coloca o indivíduo como o fundamento da ordem social e jurídica. A sociedade e as leis são entendidas como derivadas dos indivíduos por contrato, consenso ou cooperação.

É o tempo da doutrina do direito natural, isto é, das elaborações filosóficas que se fundamentam na idéia de que há atributos da natureza que igualam todos os seres humanos. Por esse caminho, vai-se justificar a construção de uma nova ordem jurídica fundada nos direitos individuais e que se expressa formalmente, pela primeira vez, na Constituição dos Estados Unidos (1787) e na Declaração dos Direitos da Pessoa Humana (França, 1789).

É também o tempo da construção do conceito de cidadão, aquele ente ativo que compõe a sociedade, tem direitos inalienáveis e de onde emerge todo o poder social (em oposição à antiga doutrina do direito divino dos governantes que justificava a ordem medieval e absolutista).

É nesse quadro que se desenvolve também um outro conceito importante para nossa reflexão - o de autor, entendido como o agente individual e solitário que cria o texto.

Esse conceito se constituiu à medida que confluíram, pelo menos, duas realidades: o estabelecimento do conceito de propriedade individual como um dos direitos naturais; e o de responsabilidade civil (a obrigação imposta pela 
ordenação jurídica de o indivíduo ser penalizado pelos prejuízos causados a outros indivíduos por seus atos, entre os quais se incluíram as atividades de produção de textos).

Com o conceito de autor, consolida-se a noção de 'propriedade intelectual' (o texto passa a ter um dono) e criam-se as bases para penalizar, seja o plágio (a apropriação considerada indébita do texto de outrem), seja a calúnia, a injúria, a difamação (prejuízos causados a outrem pelo texto de alguém).

O conceito de autor vai logo agregar valores ao ato de escrever (ao conceito de autoria) e ao produto (ao texto). $O$ pensamento romântico vai dar ênfase à idéia de autoria como um ato puramente individual e solitário: o autor, indivíduo autônomo e interiormente uno (quer dizer, o mundo interior não era ainda um problema efetivo), é, no uso de seu gênio inventivo, de sua imaginação criadora, a fonte soberana, a origem absoluta do texto. Em consequiência, a apreciação dos textos passa a se fazer sob critérios de originalidade (o 'novo' que nasce da subjetividade criadora), somando-se a ele o de autoridade textual (a significação do texto é dada apenas pelo autor e para compreender o texto é necessário recuperar informações sobre sua vida e seu pensamento. Trabalha-se com o pressuposto de que o texto tem um significado último, cuja garantia é o autor, cabendo ao leitor apenas decifrar esse significado).

\section{A desconstrução do conceito moderno de indivíduo e autor ${ }^{2}$}

Nos séculos 19 e 20, vamos assistir aos processos de desconstrução do conceito moderno de indivíduo e do conceito romântico de autor.

Para o primeiro, contribuíram particularmente as discussões teóricas de Marx e Freud (e, mais tarde, de Althusser e Lacan). De Marx, pode-se destacar, em especial, sua crítica à oposição abstrata indivíduo/sociedade (articulada a partir das teorias iluministas que davam precedência ao individual sobre o social); sua teorização de que a organização social está condicionada, em última análise, pelo modo de produção (e, portanto, não nasce do consenso entre os indivíduos); e sua argumentação de que o indivíduo não precede as relações sociais, mas tem de ser entendido a partir delas, como uma criação delas, e não o contrário.

De Freud, destacam-se as reflexões que apontam a imensa complexidade do mundo interior, mostrando que nossa psique não é a unidade racional e POSSENTI.

2 Para esta seção, nossas referências são as seguintes: BARTHES, FOUCAULT e 
consciente idealizada pelo pensamento pós-medieval, mas uma realidade fragmentada, múltipla, heterogênea que desconhece, inclusive, as artimanhas de seu próprio inconsciente e não tem controle de razão e vontade sobre elas.

Os desdobramentos posteriores do Marxismo e da Psicanálise vão tornar corrente a idéia de que a subjetividade é uma grande ilusão, partindo do princípio de que as forças da Ideologia e do Inconsciente determinam poderosamente as ações e o dizer das pessoas.

Essa perspectiva determinista chega a ser tão forte, em algumas dessas teorias, que elas acabam por assumir a tese de que nós, de fato, não falamos, mas somos falados pelas estruturas (ideológicas e/ou inconscientes) que nos submetem.

Uma observação terminológica é importante nesse ponto: falar, nessas discussões, não remete à instanciação individual do sistema gramatical (como para os lingüistas), mas às práticas discursivas, às atividades socioverbais produtoras de significações.

Estamos, portanto, diante de objetos diferentes: embora aparentemente seja o mesmo verbo falar, há aqui duas significações diferentes para ele. Vale dizer: a problematização do conceito pós-medieval de pessoa humana acabou por definir também (e por necessidade) um outro eixo para nossas discussões sobre a linguagem. Isso porque se percebe que uma reconceitualização do ser humano passa inevitavelmente por uma compreensão de suas práticas discursivas.

Isso posto, apontemos agora alguns aspectos da crítica à noção romântica de autor.

Embora essa crítica tenha-se agudizado a partir dos anos 60 (nos trabalhos, por exemplo, de Barthes e Foucault), podemos dizer que o século 20 como um todo foi, de certo modo, um século anti-autor. Lembremos, por exemplo, que várias elaborações teóricas sobre a literatura, como o Formalismo russo e o New Criticism americano, colocaram o texto como objeto central de estudo, eliminando, das preocupações teóricas, a necessidade de se remeter à vida $\mathrm{e}$ ao contexto do autor.

Nessa perspectiva, tornou-se fundamental a arquitetura, a ordem interna do texto. Mais ainda: o texto passou a ser visto não só como um artefato, mas também como uma forma atualizadora de códigos culturais que pré-existem e transcendem à autoria e, portanto, devem ser estudados em si, dispensando-se a necessidade de referência a quem está escrevendo.

Como se pode ver, é o próprio escrever que está sofrendo um processo de reconceitualização. Abandona-se a idéia de que escrever é um ato de expressão individual e passa-se a encará-lo como uma espécie de jogo interativo 
de signos. É como se disséssemos que quem 'fala' são os códigos e não quem escreve.

Em conseqüência, vai-se também perceber o texto não como uma seqüência de palavras a produzir um significado único, mas um espaço de dimensões múltiplas onde se casam e se contestam escrituras variadas, das quais nenhuma é original. O texto é percebido como um tecido de citações, saídas dos mil focos da cultura.

São, desse modo, postos em xeque os valores agregados pelo romantismo ao conceito de autor (fonte/ originalidade). Entra em circulação o termo intertextualidade, que é usado para se fazer referência exatamente à noção de que o texto é um tecido de citações, um mosaico de citações, para se explorar a complexidade e heterogeneidade dos materiais discursivos que se interseccionam na construção do texto.

O século 20 conheceu também um outro deslocamento importante nesse processo de desconstrução do conceito de autor. Trata-se da ênfase que se começou a dar ao leitor como elemento ativo na geração de significações.

Consolida-se o entendimento de que não há um significado último no texto (posto lá pelo autor soberano); não há, em consequiência, uma interpretação única, correta e final de qualquer texto. Ler não é, portanto, um gesto passivo de mera decifração desse (inexistente) significado último, mas um processo ativo e complexo de geração de significações.

Nesse sentido, veio-se a afirmar que os textos são infindamente criados pelos leitores no processo de leitura. E que esse processo não obedece a uma lógica dedutiva, mas a uma lógica do símbolo que é sempre associativa: ler implica associar ao texto, à medida que se percorrem os meandros do mosaico de citações, outras idéias, outras imagens, outros textos, outras significações.

Não nos interessa aqui ir muito além dessas considerações gerais sobre o questionamento do conceito pós-medieval de pessoa humana e do conceito de autor. Parece-nos que elas são suficientes para situar a temática que nos está interessando.

Assumiremos, na seqüência do texto, uma das várias perspectivas que procuram reinterpretar o ser humano em meio à poeira levantada pelas críticas que resumimos acima; e que nos parece adequada para sustentar o estudo das práticas discursivas que constituem nosso objeto de análise. 


\section{Nossa perspectiva teórica ${ }^{3}$}

Vamos, a partir daqui, detalhar nossa perspectiva teórica. Comecemos pela concepção de linguagem, dizendo que ela recusa a imagem de língua e de falante que apresentamos no início deste texto, isto é, a imagem de uma língua unitária (cuja descrição se resume à explicitação do sistema gramatical subjacente) e a imagem de um falante univocal que, ao falar, apenas atualiza aquele sistema.

$\hat{E}$ um outro modo de olhar a linguagem - essa realidade extremamente complexa e multiface - que vai ser posto em cena. Trata-se de centrar o olhar nas práticas discursivas, ou seja, na língua em sua integridade concreta e viva e não na língua como um objeto obtido por meio da abstração radical da vida concreta do discurso, processo este que fundamenta o olhar tradicional da Linguiistica. Por mais legítima e produtiva cientificamente que seja essa abstração, temos de reconhecer que ela tem pouco ou quase nada a dizer quando queremos entender nossas práticas discursivas.

Para esse outro modo de olhar, nenhuma língua pode ser percebida como unitária; toda realidade linguiística é sempre heteroglótica (plurilíngüe, pluridiscursiva, pluriestilística). E todo falante é igualmente percebido como uma realidade heteroglótica.

A dinâmica sócio-histórica das comunidades humanas cria múltiplos horizontes interpretativos da realidade, cada um constituindo uma certa posição avaliativa dessa realidade. Como cada horizonte avaliativo se materializa verbalmente (há uma espécie de ligação orgânica entre elementos verbais e visão de mundo), denominamos esses conjuntos verbo-axiológicos de línguas sociais. Essas línguas sociais (também chamadas de vozes sociais) são uma espécie de tecido em que se entrelaçam palavras e valores; são conjuntos difusos de visões de mundo (sistemas sociais de crenças) e elementos verbais.

É importante dizer neste ponto que, ao abordar as línguas humanas nessa perspectiva de realidades heteroglóticas, não se está tratando apenas de reconhecer e descrever dialetos ou registros como o fazem tradicionalmente as diferentes análises dialetológicas ou sociolinguiísticas, cujo foco de atenção, como vimos acima, ultrapassa pouco os elementos puramente lingüísticos. $\mathrm{Na}$ perspectiva da heteroglossia, a variação lingüística em si (fonético-fonológica e sintática) só interessa quando parte constituinte de uma língua social; quando atravessada de valores.

3 Esta seção está baseada nos textos de BAKHTIN, em especial $O$ discurso no romance e Marxismo e filosofia da linguagem. Aproveitamos, também, algumas interpretações de Bakhtin, em especial EVANS, TAYLOR E WERTSCH. 
Assume-se, nessa perspectiva que estamos apresentando, que nossas conceitualizações do mundo (materializadas verbalmente) são sempre acentuadas, são sempre perpassadas de valores. É nesse sentido que se afirma que os signos verbais refletem e refratam o mundo, significando que não há um modo neutro, objetivo, sobre-humano de se falar do mundo; os elementos verbais, na dinâmica sócio-histórica, estão sempre totalmente ensopados de valores (mesmo quando marcados pela retórica da neutralidade e da objetividade).

Mais importante, porém, do que passar a observar a língua como uma realidade heteroglótica é perceber que essas inúmeras línguas sociais coexistem numa intrincada rede de contatos; cada língua social está posta em relação com outras, em relação de harmonização ou de dissonância, de suplementação mútua, de intersecção, de contradição.

Assim, não basta estudar a heteroglossia, isto é, não basta caracterizar as línguas sociais. É preciso ir além e se envolver com a intrincada rede de relações dialógicas que se estabelecem entre as inúmeras línguas sociais, buscando explicitar os diferentes processos pelos quais se dá essa complexa dinâmica dialógica.

Interessante destacar, neste ponto, que esses processos não foram ainda suficientemente estudados (pelo menos não na dimensão em que os estamos situando aqui). Alguns tiveram certa atenção nos estudos retóricos e literários (como a ironia e a paródia), mas a maior parte ainda está por ser abordada com mais profundidade.

Para isso, é preciso, antes de tudo, mudar toda uma concepção de linguagem e, mais, perceber que esses processos não são marginais, acessórios ou apenas complementares no estudo lingüístico, mas que a vida da língua - seja na esfera da conversação cotidiana, seja em qualquer outra esfera sociocultural (artística, científica, filosófica, religiosa, política, jurídica, jornalística) - é constituída intrinsecamente de relações dialógicas entre as diferentes vozes sociais.

É essa interanimação entre as línguas sociais, essa heteroglossia dialógica, que mantém a realidade lingüística em perpétuo movimento. Em outras palavras, a realidade linguiística nunca é estática: há um permanente devir socioverbal. Da contínua tensão dialógica entre as línguas sociais, emerge um ininterrupto e inesgotável processo de violação e apagamento de fronteiras, de citações diretas, de reacentuações, de estilizações, de hibridizações, de polêmicas explícitas e implícitas. Por isso, dissemos acima que cada língua social é um conjunto difuso de visão de mundo e elementos verbais, porque as línguas sociais estão se recriando incessantemente no contexto das relações sociais. 
O estudo do que é dito (o estudo dos enunciados) deixa de ser uma questão de gramática para ser uma questão eminentemente verbo-axiológica. Isto é: deixamos de projetar os enunciados sobre um fundo gramatical e passamos a dimensioná-los na perspectiva de uma articulação discursiva. Mas não só isso. Mais importante será dimensioná-los na complexa rede dialógica que se estabelece entre as diferentes articulações discursivas, entre as diferentes vozes sociais.

Nessa perspectiva, pode-se dizer que há, em todo gesto enunciativo, uma orientação dialógica, isto é, todo enunciado, emergindo sempre no ambiente dialogicamente agitado e cheio de tensões das vozes sociais, se põe (explícita ou implicitamente) como uma resposta a outros enunciados, concordando com eles ou deles discordando, reacentuando-os ou fundindo-se com eles; parafraseando-os ou parodiando-os.

Por ser sempre resposta no diálogo social, todo enunciado instaura a possibilidade de se tornar ele mesmo alvo de respostas. Por isso, os enunciados, tendo seus interlocutores presumidos no horizonte, constroem-se direcionados, entre outros fatores, pela antecipação de algumas dessas possíveis respostas.

É nesse complexo caldo heteroglótico e dialógico que nasce e se constitui o falante. Para ele, a realidade lingüística não se apresenta primordialmente como um sistema gramatical abstrato, mas como um mundo de vozes e suas relações de aceitação e recusa, suas convergências e divergências, suas harmonias e seus conflitos, suas intersecções e hibridizações.

É nessa atmosfera que o falante vai-se construindo discursivamente, assimilando vozes sociais, isto é, absorvendo conjuntos verbo-axiológicos (o verbal e as visões de mundo nele materializadas) e, simultaneamente, suas interrelações dialógicas. É nesse sentido que se diz figurativamente que não tomamos nossas palavras do dicionário, mas dos lábios dos outros.

Como a realidade é heteroglótica, nenhum falante absorve apenas uma voz, mas sempre várias vozes. Por isso, dissemos acima que o falante é entendido, na perspectiva que estamos assumindo, como uma realidade heteroglótica. Ele não é entendido como um ente uno verbalmente, mas como um agitado balaio de vozes sociais e seus inúmeros encontros e entrechoques. $\mathrm{O}$ mundo interior, assim, é uma espécie de microcosmo heteroglótico, constituído a partir da internalização dinâmica e ininterrupta da heteroglossia social. Em outros termos, o mundo interior é uma arena povoada de vozes sociais em suas múltiplas relações de consonâncias e dissonâncias; e em permanente movimento, já que o falante está sempre imerso na interação social.

Nossos enunciados emergem - como respostas ativas que são no diálogo social - da multidão das vozes interiorizadas. Eles são, assim, compósitos de 
vozes. Desse ponto de vista, nossos enunciados são sempre discurso citado, embora nem sempre percebidos como tal, já que são tantas as vozes incorporadas que muitas delas são ativas em nós sem que percebamos sua alteridade (dizemos, então, figurativamente que são palavras que perderam as aspas).

Outras, contudo, estão na nossa memória discursiva como palavras de outrem e como tais são bivocalizadas em nossos enunciados (isto é, nossos enunciados expressam a um só tempo a palavra do outro e a perspectiva com que a tomamos): elas são citadas direta ou indiretamente, são ironizadas, parodiadas, estilizadas, hibridizadas.

O enunciado assim concebido se apresenta como uma realidade consideravelmente mais complexa e dinâmica do que quando ele é entendido simplesmente como um objeto que articula as intenções de quem o produz, isto é, quando se entende o enunciado apenas como um veículo direto e univocal da expressão individual.

Quando dizemos que, de certo ponto de vista, todo enunciado é discurso citado, podemos sugerir que o falante apenas repete os discursos e que, na perspectiva que adotamos, não há espaço para a individualidade. Estaríamos, portanto, aliados às teorias que operam com a tese de que não falamos, mas somos sempre falados.

É preciso, por isso, esclarecer que a perspectiva que adotamos recusa, ao mesmo tempo, a imagem moderna (pós-medieval) da pessoa humana e os extremos deterministas de algumas das teorias que participaram da desconstrução daquela imagem. Busca-se, alternativamente, formular um entendimento da pessoa humana na perspectiva de suas relações sociais e como um ente interiormente múltiplo e heterogêneo (aceitam-se, portanto, as críticas à concepção moderna da pessoa humana), mas procura-se manter um espaço teórico significativo para a individualidade (recusa-se o determinismo absoluto seja da Ideologia, seja do Inconsciente).

O que sustenta essa alternativa teórica é a percepção de que o universo socioideológico e o mundo interior não remetem a estruturas pesadamente monolíticas e centrípetas (como se houvera um único centro verbo-axiológico), mas a realidades infinitamente múltiplas de vozes sociais, atravessadas por uma tensão permanente entre forças centrípetas e centrífugas, e coexistindo em uma intrincada rede de incontáveis entrechoques ocorrendo numa dinâmica inesgotável.

É dessa imensa diversidade de vozes e de suas relações dialógicas que emerge como possível a individualidade que se constituirá explorando o espaço infindo da tensão dialógica das vozes sociais. 
O falante tem, desse modo, a possibilidade de individualizar-se e de individualizar seu discurso não por meio da atualização das virtualidades de um sistema gramatical (como querem a Lingüística e a Estilística), ou da expressão de uma subjetividade pré-social (como queriam os românticos), mas na interação viva com as vozes sociais. Autorar, nessa perspectiva, é orientar-se na atmosfera heteroglótica; é assumir uma posição estratégica no contexto da circulação e da guerra das vozes sociais; é explorar o potencial da tensão criativa da heteroglossia dialógica.

Essa concepção da individualidade como emergindo da heteroglossia dialógica nos fornece um instrumento interessante para analisarmos e reinterpretarmos as práticas discursivas; para refinarmos nossa percepção da realidade heteroglótica das línguas; e, igualmente, para expandirmos nossa participação ativa nos inúmeros e infindos diálogos sociais.

\section{RESUMO}

O presente trabalho problematiza a noção de falante (negligenciada por longo tempo pelos tratamentos linguísticos clássicos). Para tanto, fundamenta-se na visão bakhitiana da interação verbal e, sob essa perspectiva, rediscute as citações e a concepção de autoria.

Palavras-chave: citação, autoria, heteroglossia dialógica.

\section{ABSTRACT}

This essay renders problematic the concept of speaker (neglected for a long time by traditional approaches in Linguistics). It takes Bakhtin's view of verbal interaction as a starting point and, from that theoretical perspective, readdresses the study of citations and the concept of authorship.

Key words: citation, authorship, dialogic heteroglossia. 


\section{REFERÊNCIAS BIBLIOGRÁFICAS}

BAKHTIN, M. M. O discurso no romance. In: Questôes de literatura e estética: a teoria do romance. São Paulo: Hucitec/Ed. da Unesp, 1988. p. 71-210. 1979.

BARTHES, R. A morte do autor. In: 1988. p. 65-70.

DUMONT, L. $O$ individualismo: uma perspectiva antropológica da ideologia moderna. Rio de Janeiro: Rocco, 1993.

EVANS, F. Cognitive psychology, phenomenology, and "The Creative Tension of Voices". Philosophy and Rhetoric, v. 24, n. 2, p. 105-121. The Pennsylvania State University, 1991.

FOUCAULT, M. What is an author? In: Language, Counter-Memory, Practice. Ithaca: Cornell University Press, 1977.

HANSEN, J. A. Autor. In: JOBIM, J. L. (Org.). Palavras da crítica: tendências e conceitos no estudo da literatura. Rio de Janeiro: Imago, 1992, p.11-43.

PEASE, D. E. Author. In: LENTRICCHIA, F.; McLAUGHLIN, T. (Eds.) Critical Terms for Literary Study. 2. ed. Chicago: The University of Chicago Press, 1995. p.104117.

POSSENTI, S. Concepções de sujeito na linguagem. Boletim 13 - Associação Brasileira de Lingüística, dez. 1992, p.13-30.

TAYLOR, C. The Dialogic Self. In: HILEY, D. H.; BOHMAN, J. F.; SHUSTERMAN, R. (Eds.) The Interpretative Turn: Philosophy, Science, Culture. Ithaca: Cornell University Press, 1991. p. 304-314.

WERTSCH, J. V. Voices of the Mind: a Sociocultural Approach to Mediated Action. Cambridge (Mass.): Harvard University Press, 1991. 